\title{
O autismo infantil no âmbito escolar e suas abordagens (ex)inclusivas: revisão integrativa
}

\author{
Childhood autism in the school environment and its (ex)inclusive approaches: integrative \\ review
}

Autismo infantil en el entorno escolar y sus enfoques (ex) inclusivos: revisión integrativa

Rayssa Nascimento Vasconcellos ${ }^{1 *}$, Maria Helena do Nascimento Souza ${ }^{1}$, Juliana Andrade Pereira².

\section{RESUMO}

Objetivo: Identificar o conhecimento produzido sobre a percepção das famílias e de profissionais acerca da inclusão escolar de crianças com transtorno do espectro autista. Métodos: Trata-se de uma revisão integrativa da literatura publicada no recorte temporal de janeiro de 2016 a janeiro de 2020 nas bases de dados Literatura Latino Americana e do Caribe em Ciências da Saúde (LILACS) e Scientific Electronic Library Online (SCIELO). Resultados: Ainda há fragilidades na inclusão das crianças no ambiente escolar, o que gera sofrimento, estresse e preocupação para os familiares. A falta de uma formação acadêmica adequada reflete na escassez de profissionais qualificados para garantir a manutenção da criança na Escola. Considerações Finais: Constatou-se que há lacunas no conhecimento de familiares e profissionais sobre as formas de inclusão da criança com transtorno do espectro autista na escola necessitando de capacitação profissional para o suporte necessário à família e garantia da aprendizagem e bem-estar das crianças.

Palavras-chave: Transtorno do espectro autista, Inclusão escolar, Educação especial, Família.

\begin{abstract}
Objective: To identify the knowledge produced about the perception of families and professionals about the school inclusion of children with autism spectrum disorder. Methods: This is an integrative review of the literature published in the time frame from January 2016 to January 2020 in the databases Latin American and Caribbean Literature on Health Sciences (LILACS) and Scientific Electronic Library Online (SCIELO). Results: There are still weaknesses in the inclusion of children in the school environment, which generates suffering, stress, and concern for family members. The lack of adequate academic training reflects the scarcity of qualified professionals to ensure the maintenance of the child in school. Final considerations: It was found that there are gaps in the knowledge of family members and professionals about the ways of inclusion of children with autism spectrum disorder in school, requiring professional training for the necessary support to the family and guarantee of the learning and well-being of children.
\end{abstract}

Key words: Autism spectrum disorder, School inclusion, Special education, Family.

1 Universidade Federal do Rio de Janeiro (UFRJ), Rio de Janeiro - RJ.

*E-mail: rayvasc322@gmail.com

${ }^{2}$ Universidade Federal dos Vales do Jequitinhonha e Mucuri (UFVJM), Montes Claros - MG.

SUBMETIDO EM: 3/2021

ACEITO EM: 3/2021

PUBLICADO EM: 3/2021 


\section{RESUMEN}

Objetivo: Identificar los conocimientos producidos sobre la percepción de las familias y los profesionales sobre la inclusión escolar de los niños con trastorno del espectro autista. Métodos: Se trata de una revisión integrativa de la literatura publicada en el plazo de enero de 2016 a enero de 2020 en las bases de datos Literatura Latinoamericana y del Caribe sobre Ciencias de la Salud (LILACS) y Biblioteca Electrónica Científica en Línea (SCIELO). Resultados: Todavía hay debilidades en la inclusión de los niños en el entorno escolar, lo que genera sufrimiento, estrés y preocupación por los miembros de la familia. La falta de una formación académica adecuada refleja la escasez de profesionales cualificados para garantizar el mantenimiento del niño en la escuela. Consideraciones finales: Se encontró que hay lagunas en el conocimiento de los miembros de la familia y profesionales sobre las formas de inclusión de los niños con trastorno del espectro autista en la escuela, que requieren formación profesional para el apoyo necesario a la familia y la garantía del aprendizaje y el bienestar de los niños.

Palabras clave: Trastorno del espectro autista, Inclusión escolar, Educación especial, Familia.

\section{INTRODUÇÃO}

O transtorno do espectro autista (TEA) é caracterizado como um distúrbio genético que leva a uma alteração no neurodesenvolvimento, e é determinado por limitações na interação social, movimentos físicos de repetição e pelo atraso no desenvolvimento do sistema cognitivo, o que propicia o comprometimento do progresso natural da inteligência. Descreveu-se inicialmente, em 1943, pelo psiquiatra Leo Kanner o autismo constitui em uma doença que geralmente está acompanhado por outras patologias clínicas, incluindo distúrbios de ansiedade, depressão, distúrbio de déficit de atenção e hiperatividade, distúrbios do sono e problemas gastrointestinais (CARMO MA, et al., 2019; ZELDOVICH L, 2018; QUAAK I, 2013).

De acordo com Organização Mundial da Saúde (OMS) a prevalência internacional de TEA em 0,76\%; todavia, isso simboliza apenas cerca de $16 \%$ da população infantil mundial (BAXTER AJ, et al., 2015). A prevalência do TEA nos Estados Unidos da América mais do que duplicou entre 2000-2002 e 2010-2012, segundo estimativas da (ADDM) Rede de Monitoramento do Autismo e Deficiências do Desenvolvimento (BAIO J, et al., 2018). No Brasil estima-se a existência de cerca de 2 milhões de autistas, sendo que só no Estado de São Paulo há por volta de 300.000 ocorrências (OLIVEIRA C, 2015).

Ademais, estudos internacionais destacam a influência de fatores ambientais como uma das causas do TEA, sendo que a maior parte desses fatores se dá durante a fase do pré-natal na qual o corpo parental se encontra mais susceptível a sofrer alterações propiciadas pelo ambiente, principalmente devido a supressão do sistema imune que ocorre durante a gravidez, tornando o binômio mãe e filho passível de adquirir infecções. Desse modo tem sido associado a ocorrência de infecções virais dos pais no desenvolvimento de autismo em seus filhos (WANG C, et al., 2017).

No Brasil, o número de alunos com TEA matriculados em classes comuns ampliou 37,27 \% em um ano e embora as crianças sejam um ser humano em pleno desenvolvimento, verifica-se que aquelas em situação de TEA exibem uma maior incapacidade cognitiva, adversidades no relacionamento pessoal e na construção de vínculos, os quais são estabelecidos primeiramente com a família e com as instituições de educação, como creches e escolas (BRASIL, 2019; SILVA MM, et al., 2019).

Quanto inserção da criança com TEA no contexto escolar, a importância da sociedade se basear no paradigma dos direitos humanos que garante os direitos das pessoas com deficiência e leve em consideração as particularidades desse grupo, em especial da criança. Dessa forma, ressalta-se o papel de profissionais junto às famílias e crianças com TEA. Percebe-se, no entanto, levando em consideração à ampla carência de profissionais qualificados para o diagnóstico e acolhimento efetivo da criança autista, impasses surgem ao receber esses alunos nas instituições de ensino e o comportamento de tais profissionais e funcionários pode ser benéfico ou prejudicial tanto para criança quanto para seus cuidadores (FERREIRA MM e FRANÇA AP, 2017). 
Segundo a Lei Brasileira de Inclusão da Pessoa com Deficiência, a inserção de profissionais específicos para a educação inclusiva, como o instrutor no reforço escolar, fortalece as atividades sendo fonte de motivação, suporte e apoio, possibilitando às crianças com deficiência a realização de diversas tarefas e ações tais como: alimentação, cuidados com a higiene, transporte dentro da escola ou em qualquer outra demanda de atividade (BRASIL, 2015).

À face do exposto, a necessidade de compreender qual a configuração do contexto de inclusão educacional na infância, em situação de TEA. Mediante a isso este estudo tem como objetivo: identificar o conhecimento produzido sobre a percepção das famílias e de profissionais acerca da inclusão escolar de crianças com TEA.

\section{MÉTODOS}

Trata-se de um estudo bibliográfico, descritivo, do tipo revisão integrativa de literatura. Utilizou-se uma busca nas bases de dados, Literatura Latino Americana e do Caribe em Ciências da Saúde (LILACS) e Scientific Electronic Library Online (SCIELO) do sítio da Biblioteca Virtual em Saúde (BVS) e em bases virtuais, para seleção dos artigos. Tendo em vista a seguinte questão norteadora: Qual a percepção que profissionais e familiares têm sobre a inclusão de crianças com transtorno do espectro autista no ambiente familiar e escolar?

Deu-se no primeiro semestre de 2020, em quatro etapas. Na primeira, foram determinadas as bases de dados a serem utilizadas para a seleção dos artigos, sendo essas SCIELO, LILACS e em bases de bibliotecas virtuais. A segunda etapa consiste, em determinar as palavras chaves de acordo com os Descritores em Ciências da Saúde (DeCS).

Foram utilizadas as seguintes palavras-chave: 'Transtorno do espectro autista', 'Inclusão Escolar', 'Educação especial', 'Família'. A terceira etapa deu-se pela confecção dos critérios de inclusão e exclusão. Considerando-se artigos apresentados em português e inglês, preferencialmente dentro do recorte temporal de (2016-2020) e na íntegra. Foram excluídos deste estudo, dissertações, teses e artigos oriundos de fontes não fidedignas. E a quarta etapa, consistiu-se na leitura e análise dos artigos conforme o objetivo central deste estudo, contribuindo para elaboração dos resultados e discussão.

Utilizou-se na base de dados SciELO: "autismo" and "ensino infantil" or "inclusão" and in: ("scl") and year cluster ("2017" or "2018" or "2019" or "2020") resultando em 123 artigos, sendo as prioridades: atualidade, relevância e estudos qualitativos. Na base de dados LILACS, foram encontrados 11 artigos segundo as palavras-chaves "autismo" e "inclusão escolar, sendo selecionados 2 artigos.

Realizou-se além disso, uma pesquisa visando artigos elaborados por universidades federais e estaduais no Brasil, estes, encontrados dentro Revistas, no âmbito da educação, psicologia e saúde, de acordo com as palavras-chaves "autismo", "família", "ensino infantil" e "inclusão escolar". Visando ascender a validade metodológica desta revisão, foi utilizado o fluxograma Preferred Reporting Items for Systematic Reviews and Meta-Analyses: The PRISMA Statement (MOHER D, et al., 2009). Por conseguinte, adquiriu-se uma amostra final de 16 artigos, os quais podem ser verificados na Figura 1. 
Figura 1 - Fluxograma de seleção metodológica de artigos.

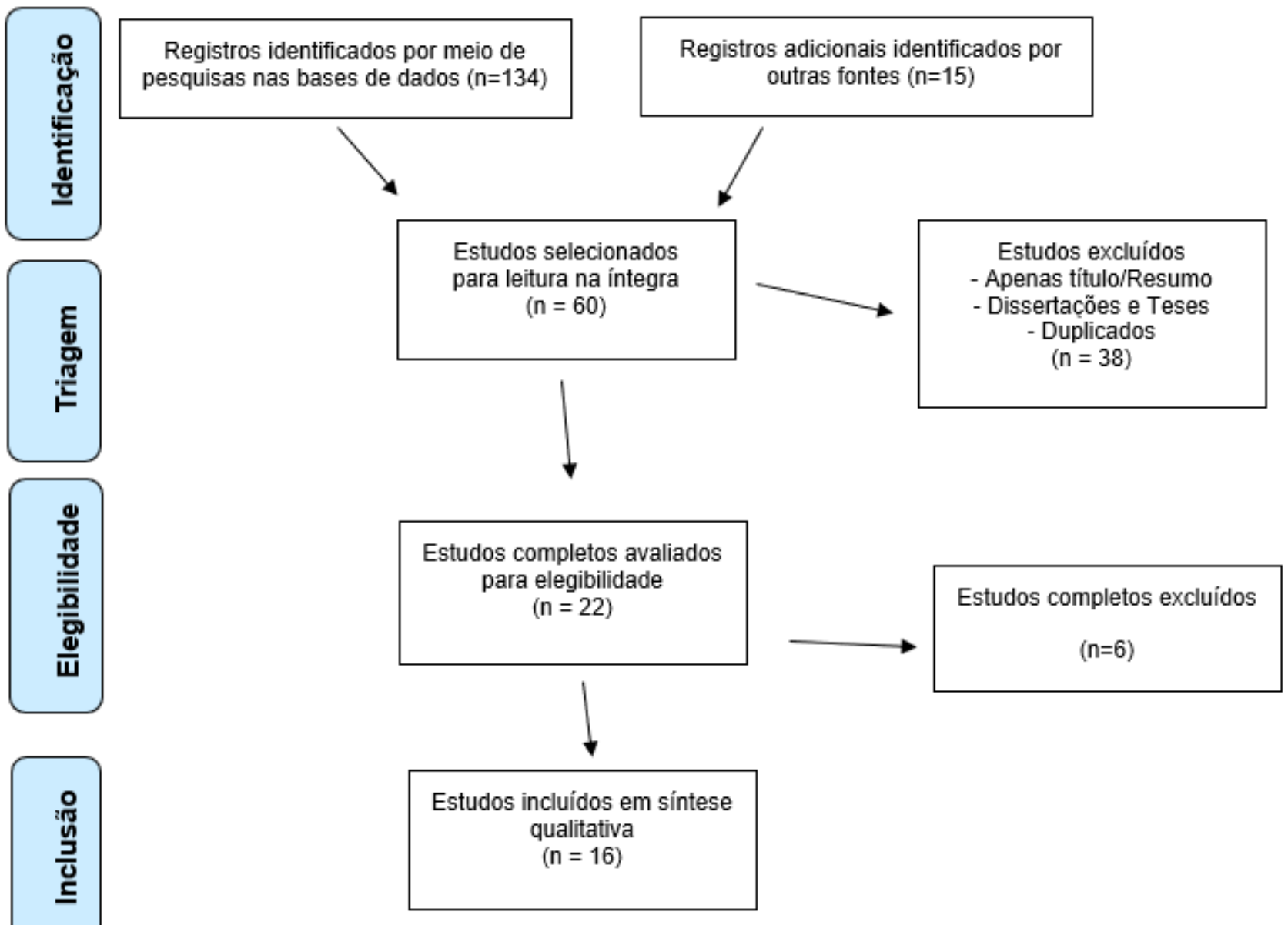

Fonte: Vasconcellos RN, et al., 2021.

\section{RESULTADOS E DISCUSSÃO}

Vislumbrando a organização das pesquisas selecionadas para esta revisão, buscou-se explicitar os artigos de acordo com os autores, ano de publicação, título, método, e os principais resultados de cada estudo. Os quais, podem ser evidenciados no Quadro 1. 
Quadro 1 - Distribuição dos artigos de acordo com os títulos, método e os principais resultados.

\begin{tabular}{|c|c|c|c|c|}
\hline $\mathbf{N}$ & Autores (Ano) & Título & Método & Principais Resultados \\
\hline 1 & $\begin{array}{l}\text { Campos CC, et al. } \\
\text { (2018) }\end{array}$ & $\begin{array}{l}\text { Expectativa de profissionais de } \\
\text { saúde e de psicopedagogos } \\
\text { sobre aprendizagem e inclusão } \\
\text { escolar de indivíduos com TEA. }\end{array}$ & $\begin{array}{l}\text { Pesquisa } \\
\text { qualitativa }\end{array}$ & $\begin{array}{l}\text { Os profissionais reconhecem a inclusão escolar como um fator motivador do } \\
\text { aprendizado e da inserção da criança, contudo, há desafios que dificultam sua } \\
\text { aplicabilidade, como preparo e formação suficientes. Entretanto, nota-se que a } \\
\text { presença de atividades físicas e música auxiliam e colaboram como } \\
\text { desenvolvimento da criança com autismo, sendo estas, ações que favorecem a } \\
\text { comunicação. }\end{array}$ \\
\hline 2 & $\begin{array}{l}\text { Rederd BF, et al. } \\
\qquad(2018)\end{array}$ & $\begin{array}{l}\text { Autismo diante do raciocínio } \\
\text { lógico matemático: fatores } \\
\text { determinantes e métodos de } \\
\text { intervenção. }\end{array}$ & $\begin{array}{l}\text { Pesquisa } \\
\text { qualitativa }\end{array}$ & $\begin{array}{l}\text { Os profissionais da escola adotam estratégias a fim de estimular a cognição e } \\
\text { socialização da criança, como métodos de intervenção ABA e PECS. Quanto ao seu } \\
\text { uso, constatou-se uma repercussão positiva no cotidiano, dito que possibilita a } \\
\text { melhora dos alunos com TEA no que tange a independência e autonomia. }\end{array}$ \\
\hline 3 & $\begin{array}{l}\text { Santos AA, et al. } \\
(2020)\end{array}$ & $\begin{array}{l}\text { Olhar da família e da escola } \\
\text { para a criança com TEA. }\end{array}$ & $\begin{array}{l}\text { Pesquisa } \\
\text { exploratória }\end{array}$ & $\begin{array}{l}\text { Pontua-se que é a família quem detecta comportamentos diferentes do que lhe é } \\
\text { considerado normal, primeiramente. Destaca-se que cabe à família e a escola } \\
\text { observar as crianças com TEA e seus respectivos perfis com atenção, visando } \\
\text { reduzir/perceber situações de bullying e adversidades, contemplando toda sua } \\
\text { essência emocional ao trabalhar no sentido de que a criança seja bem entendida. }\end{array}$ \\
\hline 4 & $\begin{array}{c}\text { Campos LK e } \\
\text { Miranda FF (2016) }\end{array}$ & $\begin{array}{l}\text { Perfil escolar e as habilidades } \\
\text { cognitivas e de linguagem de } \\
\text { crianças e adolescentes do } \\
\text { espectro do autismo. }\end{array}$ & $\begin{array}{l}\text { Pesquisa } \\
\text { qualitativa }\end{array}$ & $\begin{array}{l}\text { Evidenciou-se o quão essencial é o diagnóstico correto/intervenção prévia, exercida } \\
\text { por uma a equipe multiprofissional qualificada, a fim de alcançar o bom } \\
\text { desenvolvimento das crianças com autismo. Percebe-se além disso, o quão } \\
\text { necessário é o processo de inclusão educacional, visto que é capaz de propiciar o } \\
\text { avanço de habilidades cognitivas, sociais e motoras. No entanto, para tal, nota-se a } \\
\text { carência de planos pedagógicos, profissionais e atendimento educacional } \\
\text { adequados. }\end{array}$ \\
\hline 5 & $\begin{array}{c}\text { Filho AL, et al. } \\
\qquad(2016)\end{array}$ & $\begin{array}{l}\text { A importância da família no } \\
\text { cuidado da criança autista. }\end{array}$ & $\begin{array}{l}\text { Pesquisa } \\
\text { qualitativa }\end{array}$ & $\begin{array}{l}\text { Quanto aos pais, no instante em que as crianças não interagem como o estimado } \\
\text { Ihes desperta uma desconfiança perante a algum transtorno /deficiência que a } \\
\text { criança possa ter. Inicia-se então uma trajetória difícil a partir do diagnóstico. Mostra- } \\
\text { se ainda reações diferentes, e não necessariamente surpresas ou negativas visto } \\
\text { que alguns pais já possuem filhos com outras deficiências, então já possuem alguma } \\
\text { percepção no que tange a rotina. Porém os pais afirmam, não ter obtido instrução } \\
\text { dos profissionais que possuem experiência com os diagnósticos e tratamento de } \\
\text { crianças com autismo. }\end{array}$ \\
\hline
\end{tabular}




\begin{tabular}{|c|c|c|c|c|}
\hline $\mathbf{N}$ & Autores (Ano) & Título & Método & Principais Resultados \\
\hline 6 & $\begin{array}{c}\text { Silva JM e } \\
\text { Engelbrech TM } \\
(2019)\end{array}$ & $\begin{array}{l}\text { Educação especial na } \\
\text { perspectiva inclusiva: interação } \\
\text { entre escola e família. }\end{array}$ & $\begin{array}{l}\text { Pesquisa } \\
\text { qualitativa }\end{array}$ & $\begin{array}{l}\text { Observa-se, que quando os profissionais da escola contatam alguma deficiência em } \\
\text { seus alunos, informam a situação e a necessidade de os pais cooperarem do } \\
\text { cotidiano escolar de seus filhos, o que não propicia uma reação positiva. Ademais, } \\
\text { os pais relatam que quando requisitados na escola, no geral é para abordar } \\
\text { questões no que se refere a conflitos e não ao progresso acadêmico, revelando } \\
\text { pouca apreensão quanto ao bem-estar de seus filhos. }\end{array}$ \\
\hline 7 & $\begin{array}{l}\text { Semesato MR e } \\
\text { Bosa CA (2017). }\end{array}$ & $\begin{array}{l}\text { Beliefs Indicating parental } \\
\text { resilience in the context of } \\
\text { autism. }\end{array}$ & $\begin{array}{l}\text { Pesquisa } \\
\text { qualitativa }\end{array}$ & $\begin{array}{l}\text { Há um senso de desamparo na percepção dos pais, dito que, suas aflições e } \\
\text { perspectivas do processo inicial do diagnóstico não eram atendidas com a devida } \\
\text { atenção pelos profissionais envolvidos com destaque para os pediatras, os quais } \\
\text { não esclareciam diversas dúvidas quanto ao desenvolvimento e a situação do } \\
\text { autismo. Em contraste, os pais revelaram também senso de amparo no que tange } \\
\text { a relação, visto que a situação de seus filhos propiciou mais diálogo e interação } \\
\text { quanto casal. }\end{array}$ \\
\hline 8 & $\begin{array}{c}\text { Silva CL, et al. } \\
(2018)\end{array}$ & $\begin{array}{l}\text { The teaching- learning process } \\
\text { of a student with autism: a case } \\
\text { study in an inclusive school. }\end{array}$ & $\begin{array}{l}\text { Pesquisa } \\
\text { qualitativa }\end{array}$ & $\begin{array}{l}\text { Quanto a educação inclusiva os professores relataram que obtiveram tal contato } \\
\text { durante a graduação, porém conciliado com a disciplina de Libras o que possibilitou } \\
\text { uma relação superficial com o contexto de inclusão. E entende-se pelos professores } \\
\text { que o processo de inclusão exige muita atenção no âmbito escolar, sendo } \\
\text { necessária mediante a crescente inserção de alunos com deficiência nas salas de } \\
\text { aula e, especialmente por a Educação ser um direito referente à toda população. E } \\
\text { na visão inclusiva, utiliza-se estratégias de forma adaptada, como de socialização e } \\
\text { aulas de vídeo, visando estimular os alunos. }\end{array}$ \\
\hline 9 & $\begin{array}{l}\text { Fadda GM e Cury } \\
\text { VE (2019) }\end{array}$ & $\begin{array}{l}\text { The experience of parents in } \\
\text { the relationship with their child } \\
\text { diagnosed with autism. }\end{array}$ & $\begin{array}{l}\text { Pesquisa } \\
\text { qualitativa }\end{array}$ & $\begin{array}{l}\text { Os participantes receberam o diagnóstico de seus filhos quando estes, se } \\
\text { encontravam numa faixa etária de } 6 \text { anos de idade. E diante desse diagnóstico os } \\
\text { pais viam a necessidade de reinventar-se a cada dia, auxiliando seus filhos a se } \\
\text { comunicar, manusear brinquedos, e a se proteger de situações que lhes afetassem } \\
\text { a segurança. E nessa ocasião, viam-se apreensivos quanto ao futuro, e pela } \\
\text { possibilidade de seus filhos não serem bem cuidados, caso não pudessem contar } \\
\text { com sua presença, dito que a maioria dos entrevistados já se encontravam em idade } \\
\text { avançada. Ainda se relatou que a escola é, basicamente o único ambiente onde } \\
\text { pais e filhos com autismo recebem apoio social. }\end{array}$ \\
\hline
\end{tabular}




\begin{tabular}{|c|c|c|c|c|}
\hline $\mathbf{N}$ & Autores (Ano) & Título & Método & Principais Resultados \\
\hline 10 & $\begin{array}{l}\text { Ponce JO e Abrão } \\
\text { JL (2019) }\end{array}$ & $\begin{array}{l}\text { Autismo e inclusão no ensino } \\
\text { regular: o olhar dos } \\
\text { professores sobre esse } \\
\text { processo. }\end{array}$ & $\begin{array}{l}\text { Pesquisa } \\
\text { qualitativa }\end{array}$ & $\begin{array}{l}\text { Há a necessidade de receber suporte para saber laborar com as crianças, dado que } \\
\text { reconhecem que não tiveram formação adequada. Além de reconhecerem que para } \\
\text { atingir uma educação inclusiva efetiva é necessário trabalhar e trocar saberes em } \\
\text { conjunto. E quanto ao suporte da SME, considerou-se efetivo no esclarecimento de } \\
\text { incertezas também por oferecer palestras. Destaca-se além disso os desafios, como } \\
\text { as raras ocasiões de aprender com outras crianças sem o diagnóstico de TEA, } \\
\text { evidenciando preocupação, pela possibilidade de outras crianças terem que lidar } \\
\text { com esse contexto de inclusão fora do âmbito escolar. }\end{array}$ \\
\hline 11 & $\begin{array}{l}\text { Neves AT, et al. } \\
\text { (2017) }\end{array}$ & $\begin{array}{l}\text { O processo de inclusão de } \\
\text { crianças com necessidades } \\
\text { especiais de saúde na } \\
\text { educação. }\end{array}$ & $\begin{array}{l}\text { Pesquisa } \\
\text { qualitativa }\end{array}$ & $\begin{array}{l}\text { O professor necessita adaptar-se de acordo com a realidade de cada turma, dito } \\
\text { que a preocupação com a inclusão educacional e sua aplicabilidade ocorre de } \\
\text { acordo com a prática do cotidiano, mediante a procura por conhecimento e } \\
\text { reorganização de metas educacionais. Nota-se dessa forma, que a inclusão } \\
\text { CRIANES no âmbito escolar ocorre, e faz parte do dia a dia escolar. }\end{array}$ \\
\hline 12 & $\begin{array}{l}\text { Lima SM e Laplane } \\
\qquad \text { AL (2016) }\end{array}$ & $\begin{array}{l}\text { Escolarização de Alunos com } \\
\text { Autismo. }\end{array}$ & $\begin{array}{l}\text { Pesquisa } \\
\text { qualitativa }\end{array}$ & $\begin{array}{l}\text { Quanto a frequência dos alunos com TEA que, eles não completam a trajetória } \\
\text { escolar e que nesse processo de escolarização a minoria consegue alcançar o } \\
\text { ensino médio. A taxa de desvio escolar é elevada, e até mesmo alunos que estão } \\
\text { matriculados nas séries e anos proporcionais à sua faixa etária, não comparecem } \\
\text { de forma regulas às suas respectivas turmas. Além disso, uma minoria comparece } \\
\text { as assistências educacionais qualificadas e, infelizmente a rede estadual não dispõe } \\
\text { de nenhum tipo de suporte para esse grupo específico. E a rede do município } \\
\text { centraliza matrículas principalmente na escola regular e no ensino fundamental. }\end{array}$ \\
\hline 13 & $\begin{array}{l}\text { Gaia C } \\
(2016)\end{array}$ & $\begin{array}{l}\text { Autismo Infantil: proposições } \\
\text { para minimizar impactos do } \\
\text { transtorno enfrentado pelos } \\
\text { pais. }\end{array}$ & $\begin{array}{l}\text { Pesquisa } \\
\text { exploratória }\end{array}$ & $\begin{array}{l}\text { Nota-se que há pouco conhecimento no que tange a evolução e as características } \\
\text { dos distúrbios/transtornos e as respectivas instituições especializadas no contexto, } \\
\text { que acomete em especial as crianças. Ademais constatou-se que os componentes } \\
\text { das redes sociais desses indivíduos, como família e escola não depositam a } \\
\text { esperança e a importância necessária no contexto, como, possíveis práticas } \\
\text { capazes de reduzir conflitos familiares e escolares. Outra dificuldade, está na família } \\
\text { perceber a questão de maneira prévia o que afeta no convívio comportamental da } \\
\text { criança com TEA. }\end{array}$ \\
\hline
\end{tabular}




\begin{tabular}{|c|c|c|c|c|}
\hline $\mathbf{N}$ & Autores (Ano) & Título & Método & Principais Resultados \\
\hline 14 & $\begin{array}{c}\text { Rosa FD, et al. } \\
\text { (2019) }\end{array}$ & $\begin{array}{l}\text { Escolarização de pessoas com } \\
\text { Transtornos do Espectro } \\
\text { Autista (TEA) em idade adulta: } \\
\text { relatos e perspectivas de pais e } \\
\text { cuidadores de adultos com } \\
\text { TEA. }\end{array}$ & $\begin{array}{l}\text { Pesquisa } \\
\text { qualitativa }\end{array}$ & $\begin{array}{l}\text { No que se refere a escolarização na fase infantil e juvenil, que a maior parte } \\
\text { comparecia a escolas especiais e regulares de maneira sincrônica, contudo a } \\
\text { admissão ocorreu majoritariamente nas escolas regulares. Relatou-se também que } \\
\text { conflitos e aflições ocorreram somente na fase inicial, devido a necessidade de } \\
\text { adaptação, preconceito e desafios sociais. Destacou-se o qual essencial é a } \\
\text { presença e o acompanhamento junto aos profissionais especializados, de acordo } \\
\text { com as individualidades de cada criança. }\end{array}$ \\
\hline 15 & $\begin{array}{l}\text { Lemos EL, et al. } \\
(2020)\end{array}$ & $\begin{array}{c}\text { Transtorno do Espectro Autista } \\
\text { e Interações Escolares: Sala } \\
\text { de Aula e Pátio. }\end{array}$ & $\begin{array}{l}\text { Pesquisa } \\
\text { qualitativa }\end{array}$ & $\begin{array}{l}\text { Constatou-se que o autismo muitas vezes não está relacionado a fatores que } \\
\text { impossibilitam a interação, e assim destaca-se a relevância dos pais em verificar a } \\
\text { comunicação dentro dos diversos cenários. Notou-se uma relação reduzida entre } \\
\text { os colegas da escola, revelando a necessidade a intervenção das professoras a fim } \\
\text { de favorecer a comunicação harmônica em sala de aula. }\end{array}$ \\
\hline 16 & $\begin{array}{l}\text { Carvalho BS e } \\
\text { Nascimento LF } \\
\text { (2015) }\end{array}$ & $\begin{array}{c}\text { O autista e sua inclusão nas } \\
\text { escolas particulares da cidade } \\
\text { de Teresina - PI. }\end{array}$ & $\begin{array}{l}\text { Pesquisa } \\
\text { qualitativa }\end{array}$ & $\begin{array}{l}\text { A pertinência da cooperação e dedicação dos pais, auxiliando na inclusão social } \\
\text { objetivando compreender a criança de forma universal, não só suas limitações, mas } \\
\text { sim, também suas possíveis habilidades. Quanto a escola evidenciou-se que para } \\
\text { atender esse grupo os funcionários deveriam adequar-se a novos métodos e } \\
\text { estratégias o que resultaria no aumento de custos e por sua vez, na mensalidade. }\end{array}$ \\
\hline
\end{tabular}

Fonte: Vasconcellos RN, et al., 2021. 
Emergiu-se, de acordo com a análise de conteúdo três categorias, são elas: Percepção da família acerca da situação das crianças com autismo no âmbito familiar e escolar, $O$ autismo infantil na visão dos profissionais e Contexto de inclusão da criança com autismo nas escolas.

\section{Percepção da família acerca da situação de autismo das crianças no âmbito escolar e familiar}

Quando o processo de gravidez tem início, toda a família, principalmente a mãe, criam planos e projetos para a vida futura. Na fase do nascimento, não é diferente e essa percepção se direciona para as expectativas do desenvolvimento da criança de acordo com as respectivas faixas etárias, contudo, quando há alguma deficiência ou transtorno esse progresso natural é interrompido e/ou passa por atraso. Isto, leva família a buscar atendimento especializado, confirmando a deficiência/ transtorno, sendo uma etapa vista com naturalidade ou como uma espécie de "luto" pelos familiares (FILHO AL, et al., 2016).

Quando a família recebe o diagnóstico constatando que a criança possui algum transtorno mental ou atraso no desenvolvimento cognitivo/motor, percebe-se que geralmente é figura materna a mais envolvida nos tratamentos e cuidados bem como na rotina escolar (FADDA GM e CURY VE, 2019). O que corrobora com os dados de um estudo, no qual contatou-se que dentre os familiares das pessoas em situação de TEA 49 (73,13\%), possuía grau de parentesco mãe (MATSUKURA RFS, et al., 2019).

Nessa perspectiva, a interação entre a família e os profissionais da escola é essencial para a desenvoltura no processo de aprendizagem da criança, uma vez que isso propicia uma relação de confiança e unidade entre a família e a escola. Os familiares demonstraram aflição, pois relataram que na maioria das vezes são convocados à escola apenas quando seus filhos apresentam algum aspecto negativo, como mau comportamento, dificuldade nas metas curriculares ou notas abaixo do mínimo exigido pelas instituições. Se torna uma situação preocupante, dito que mesmo diante do diagnóstico de TEA as crianças são capazes de apresentar muitos aspectos positivos (SILVA JMA e ENGELBRECHT MR, 2019).

Em um estudo realizado em Brasília as ações desenvolvidas pelas crianças autistas em: senso de amparo (positivas) e senso de desamparo (negativas) evidenciando que limitações comportamentais, na fala e cognitivas exercidas por crianças resulta em um senso de desamparo na percepção dos pais, em contraste com habilidades emocionais, de afeto e de aspectos intelectuais os quais propiciam um senso de amparo. Percebe-se que as alterações biopsicossociais desse grupo não se limitam a apenas fatores negativos, mas também a traços de afeto e carinho, no que tange principalmente a família e o âmbito escolar visto que, dentro desses grupos a criança desenvolve suas primeiras relações (SANTOS AAD, et al., 2020; SILVA CL, et al., 2018).

Vislumbrando a escola, o maior número de familiares referenciou-se a essa fase como de muita dificuldade devido à falta de conhecimento acerca da temática, das práticas aplicáveis a fim de facilitar o aprendizado voltado para esse grupo, falta de base e diálogo entre os profissionais e o sentimento de impotência, visto que o autismo tem uma demanda multiprofissional e a falta de estrutura implicou nos desafios em buscar estrutura dentro do sistema público de saúde. Percebe-se o estresse, uma vez que o termo "inclusão" não era desenvolvido de forma efetiva pelas escolas, na época da infância de seus filhos o que lhes gerou um desgaste no relacionamento família - escola (FILHO Al, et al., 2016; FADDA GM e CURY VE, 2019).

Inclusive, a inserção da criança na escola também foi relatada como árdua apenas no início, devido a necessidade de adaptação. E proveitosa, dinâmica e boa no decorrer do processo, sendo um ambiente que propiciou o desenvolvimento de competências, como independência, a prática de atividades eletivas (capoeira e música) o que estimulou a estrutura neuronal e por sua vez cognitiva e motora (MATSUKURA RFS, et al., 2019; SANTOS AAD, et al., 2020).

A escola foi referenciada também, como rede de apoio sendo fonte de amparo para as pais, em especial pelo potencial de impulsionar essa rede, vista como uma extensão da família, com pais e familiares de outras redes, as quais, tem no centro uma criança com autismo e a rede de apoio formal composta por serviços de saúde, instituições de educação e dentre outras. Classifica-se, de acordo com os pais a escola classificada como uma forte forma de apoio, visto que é nesse local onde seus filhos desenvolvem as maiores relações e onde os profissionais e crianças os apreendem bem (SEMESATO MR e BOSA MR, 2019). 


\section{O autismo infantil na visão dos profissionais}

Nota-se que as primeiras características do autismo são percebidas nos primeiros dois anos do ciclo vital, ou seja, na fase pré-escolar (CARMO MA, et al., 2019; SILVA MM, et al., 2019). Dentre os principais aspectos do comportamento da população infantil em situação de TEA está a dificuldade na comunicação, de pertencer a um grupo social, estabelecer vínculos, e alterações de humor podendo ser propiciadas por um motivo eminente, ou não.

Diante de um levantamento realizado no Censo da Educação Básica em Atibaia- SP no período de (20092012), buscou-se analisar o perfil das matrículas escolares de acordo com o sexo. Constatou-se uma maior prevalência de matrículas provenientes do sexo masculino, no qual $51(76,12 \%)$ dos participantes eram do gênero masculino. O que corrobora com a literatura, na qual a maioria dos casos de autismo ocorre em homens, cerca de quatro vezes a mais do que em mulheres (LIMA SM e LAPLANE ALF, 2016).

Os aspectos do comportamento autista podem dificultar o processo de ensino e aprendizagem. Uma vez que, $65 \%$ dos professores relataram mediante entrevista a ausência de ações agressivas e violentas, mesmo perante situações de estresse das crianças, tornando inferior à metade os fatores negativos evidenciados de acordo com estereótipos referidos pela sociedade. Nessa ocasião, destaca-se um comportamento marcado por um estado ansioso e inquieto como correr e gritar, e não pela repercussão agressiva com os colegas em sala de aula e com professores, sendo este, percebido mais no início do cotidiano escolar sendo decrescente com a convivência com a turma e professores (CARVALHO BS e NASCIMENTO LF, 2015).

Em contraste, as professoras evidenciaram uma posição estreita a agressividade em crianças com TEA, perante situações que não fossem de seu agrado como a ânsia por adquirir um brinquedo em uso de outras crianças. O que em parte limita a percepção dos professores e os leva a compreender que a agressividade faz parte da vivência cotidiana dessas crianças, no geral. Além disso, há a ideologia de que a pessoa autista possui habilidades e aptidões intelectuais em atividades específicas, ou dom especial o que em sua maioria é motivo de frustração das professoras (PONCE JO e ABRÃO JLF, 2019).

Mediante um levantamento propiciado por equipe multiprofissional, composta majoritariamente por profissionais especializados em transtornos e deficiências, a percepção das características das pessoas com TEA podem ser divididas da seguinte forma: Déficit na interação social, interesses particulares e repetitivos, alterações no comportamento, na comunicação e aparecimento precoce dos sinais/sintomas, heterogeneidade na apresentação e no nível de severidade dos sintomas, e psicose. Considera-se a psicose como uma ruptura do ego e do vínculo com a figura materna, estando a criança imersa em um mundo particular, de forma constante, se deligando do ambiente externo, além da dificuldade em caracterizar o TEA (CAMPOS CC, et al., 2018).

Outrossim, existem diversas concepções de autismo, e por meio destas é possível estabelecer ações terapêuticas e didáticas, no geral, vislumbrando a inclusão dessas crianças com o perfil de TEA. Mediante os depoimentos evidencia-se o conhecimento reduzido da equipe multiprofissional perante esse grupo, levando a complexidades no momento de qualificar o TEA, traçando possíveis justificativas, tais como: os múltiplos sintomas e a carência de formação adequada frente ao conteúdo (SILVA CL, et al., 2018; GAIA C, 2016; CAMPOS CC, et al., 2018).

\section{Contexto de inclusão da criança com autismo nas escolas}

Ao analisar a inserção dos indivíduos com TEA na infância em uma pesquisa com 67 participantes residentes em diversas regiões do Brasil, identificou-se que a maioria das pessoas com autismo integraram escolas especiais $(38,98 \%)$, quanto aos que constituíram escolar especiais e regulares de forma simultânea corresponde a $(33,90 \%)$, e no que se refere as pessoas que frequentaram apenas escolas regulares equivale a $(27,12 \%)$, contudo, poucos alcançaram o ensino superior (MATSUKURA RFS, et al., 2019).

Nessa visão, quando o professor se depara com a criança em situação de TEA há a percepção de que existe uma distância entre o aluno e a figura do mestre. Visto que, diante dos conteúdos estudados acerca de crianças com necessidades especiais de saúde (CRIANES) no período de formação, tornam-se 
insuficientes as ferramentas para garantir sua aplicabilidade na prática pedagógica, propiciando a sensação de fracasso (PONCE JO e ABRÃO JLF, 2019).

Constatou-se inclusive que, as línguas estrangeiras também fazem parte da grade curricular das crianças tanto nas escolas de ensino comum quanto nas especiais, porém, enquanto outras disciplinas têm diferentes horários e encontros durante a semana, matérias como o inglês possuem apenas um encontro a cada sete dias, em um período de 45 minutos. Propiciando um menor contado de alunos com TEA e, por conseguinte um aprendizado mais custoso (PONCE JO e ABRÃO JLF, 2019; SILVA CL, et al., 2018).

Dito isso, há a preocupação e os professores veem-se pressionados a elaborar diversas estratégias didáticas, considerando esse mínimo intervalo. Ademais, evidenciou-se que houve uma redução da carga horária nos últimos anos e ao longo da história, revelando que as políticas educacionais sempre deram uma importância inferior no que se refere a conteúdos pertinentes ao âmbito escolar (SILVA C, et al., 2018).

Nota-se que esse despreparo leva os professores a buscarem especializações além da graduação e, até mesmo professores que possuem qualificação em Educação inclusiva deparam-se com a falta de base para lidar com essas crianças no cotidiano. A inclusão escolar não deve ser resumida apenas ao professor, mas sim a toda rede de ensino envolvida, tornando necessária a desenvoltura de um trabalho inclusivo em conjunto em prol do aprendizado da criança, visando que elas sejam capazes de alcançar as metas curriculares e de socialização (PONCE JO e ABRÃO JLF, 2019).

Quanto à frequência, que no intervalo de quatro anos (2009-2012) a maioria das crianças em situação de autismo próxima teve sua trajetória escolar interrompida, explicitando $46(48,93) \%$ de uma amostra de 94 alunos, sugerindo prejuízo no percurso da escolarização. Além disso, que a gestão escolar se refere a uma grande adversidade quanto a busca de professores especializados nesta e em outras áreas, devido a isso, a rede estadual de ensino abrange apenas alunos em situação de Síndrome de Asperger, ou seja, um estado do espectro autista no qual a comunicação e a cognição não demonstram atraso (LIMA SM e LAPLANE ALF, 2016).

Há estudos que também expõem essa baixa frequência, porém ligada aos seus fatores geradores, sendo os principais: os atendimentos multiprofissionais especializados, exercidos fora do âmbito escolar e que inviabilizam a presença das crianças em determinados dias, ou a continuidade no decorrer do intervalo escolar daquele dia; a instituição de ensino determina os dias que deverão ocorrer a falta dos alunos; a questão comportamental e/ou clínica não possibilita a criança conseguir manter-se por muito tempo; seguido da opção da mãe em não levar o filho à escola; por não possuir um profissional especializado na terapêutica das crianças com TEA ou devido a mãe necessariamente ter que estar com a criança na escola (NEVES AT, et al., 2017).

Contudo, os professores também consideram importante e se preocupam com a inclusão de alunos com TEA, por mais que não possuam formação adequada. Percebe-se, que buscam na prática, estratégias voltadas para comunicação capazes de despertar o interesse e curiosidade, a fim de auxiliar e facilitar a inserção desses alunos. Em contraste com escolas de rede pública do Município de Matelândia-PR que possuem Salas de Recursos Multifuncionais (SRM) para onde as crianças são encaminhadas após o laudo de deficiências/transtornos e avaliação de profissionais como neurologistas e psicopedagogos, o que possibilita à criança superar os limites (SILVA JMA e ENGELBRECHT MR, 2019).

Depreende-se que há diversos métodos, desde o brinquedo terapêutico, rodas de conversa e brincadeiras (SANTOS AAD, et al., 2020; LEMOS ELM, et al., 2020). Inclusive métodos de raciocínio lógico, e quando questionadas acerca de quais métodos matemáticos utilizavam, as professoras referenciaram dois: a Análise Aplicada do Conhecimento (ABA) que possui como objetivo fazer com que o autista formule habilidades que o possibilite ser mais autossuficiente e o método de Sistema de comunicação por figuras (PECS) sendo usado principalmente em crianças que possuem comunicação dificultosa, ou a ausência dela. Sendo baseado na troca de imagens conforme o desejo da criança tais métodos, viabilizam uma melhora gradual de acordo com a visão das professoras (REDERD BF, et al., 2018; CAMPOS LK e MIRANDA FFD, 2016). 


\section{CONSIDERAÇÕES FINAIS}

Constatou-se que há impasses na rotina escolar, devido a carência de formação adequada dos professores e ademais profissionais, sentimento de impotência ou falta de entendimento quanto no as características comportamentais dessas crianças que, às vezes são estereotipadas apenas quanto aos seus aspectos negativos, o que dificulta o aprendizado e desenvolvimento infantil. Além de lacunas no conhecimento de familiares e profissionais sobre as formas de inclusão da criança com transtorno do espectro autista na escola necessitando de capacitação profissional para o suporte necessário à família e garantia da aprendizagem e bem-estar das crianças com autismo. Portanto, faz-se necessário o diálogo, a busca por capacitação adequada e possíveis reformas curriculares na graduação, vislumbrando a melhora e conscientização gradual da sociedade, em especial, de profissionais como fonoaudiólogos, psicopedagogos, terapeutas e enfermeiros, estes, a fim de prover discussões, impulsionar debates e facilitar o relacionamento entre a escola-família.

\section{AGRADECIMENTOS}

Programa Institucional de Bolsas de Iniciação Científica (PIBIC).

\section{REFERÊNCIAS}

1. BAIO J, et al. Prevalence of Autism Spectrum Disorder Among Children Aged 8 Years-Autism and Developmental Disabilities Monitoring Network, 11 Sites, United States, 2014. Mmwr. Surveill. Summ. 2018; 67(6): 1-23.

2. BAXTER AJ, et al. The epidemiology and global burden of autism spectrum disorders. Psychol Med. $2015 ; 45$ (3): 601-613.

3. BRASIL. Lei oㅜ 13.146, de 6 de julho de 2015. Institui a Lei Brasileira de Inclusão da Pessoa com Deficiência (Estatuto da Pessoa com Deficiência). Diário Oficial da União, Brasília, DF, 7 jul. 2015. Seção 1, p. 2.

4. BRASIL. Ministério da educação, Instituto Nacional de Estudos e Pesquisas Educacionais Anísio Teixeira (Inep). Glossário da Educação Especial Censo Escolar 2019.

5. CAMPOS CC, et al. Expectativa de profissionais da saúde e de psicopedagogos sobre aprendizagem e inclusão escolar de indivíduos com transtorno do espectro autista. Revista Psicopedagogia. 2018; 35(106): 3-13

6. CAMPOS LK, MIRANDA FFD. Perfil escolar e as habilidades cognitivas e de linguagem de crianças e adolescentes do espectro do autismo. CoDAS. 2016; 28(3): 234-243.

7. CARMO MA, et al. O ambiente familiar e o desenvolvimento da criança com autismo Rev enferm UFPE on line. 2019; 13(1):206-15.

8. CARVALHO BS, NASCIMENTO LF. O autista e sua inclusão nas escolas particulares da cidade de Teresina - PI. Rev. Educ. Esp. 2015; 28 (53): 677-690.

9. FADDA GM, CURY VE. The experience of parents in the relationship with their child diagnosed with autism. Pisc: teor. Pesq. 2019; 35(esp): e35nspe2.

10. FERREIRA MM, FRANÇA AP. O Autismo e as Dificuldades no Processo de Aprendizagem Escolar. Id online Rev. Mult. Psic. 2017; $11(38)$ 507-519.

11. FILHO AL, et al. A importância da família no cuidado da criança autista. Rev. Saúde em Foco. 2016 ; 3 (1): $66-83$

12. GAIA, C. Autismo Infantil: proposições para minimizar impactos do transtorno enfrentado pelos pais. Rev. Margens Interdisciplinar. 2016; 8(10): 319-330.

13. LEMOS ELM, et al. Transtorno do Espectro Autista e Interações Escolares: Sala de Aula e Pátio. Rev. bras. educ. espec. 2020; 26 (1): 69-84.

14. LIMA SM, LAPLANE ALF. Escolarização de Alunos com Autismo. Rev. bras. educ. espec. 2016; 22 , (2) $269-284$.

15. MATSUKURA RFD, et al. Escolarização de pessoas com Transtornos do Espectro Autista (TEA) em idade adulta: relatos e perspectivas de pais e cuidadores de adultos com TEA. Cad. Bras. Ter. Ocup. 2019; 27(2): 302-316.

16. MOHER D, et al. The PRISMA Group (2009). Preferred Reporting Items for Systematic Reviews and Meta-Analyses: The PRISMA Statement. PLoS Med 6(7): e1000097.

17. NEVES AT, et al. O processo de inclusão de crianças com necessidades especiais de saúde na educação. Rev Enferm UFSM. 2017; 7(3): 374-387.

18. OLIVEIRA C. Um retrato do autismo no Brasil. Espaço Aberto - USP, 2015.

19. PONCE JO, ABRÃO JLF. Autismo e inclusão no ensino regular: o olhar dos professores sobre esse processo. Estilos Da Clínica. 2019; 24(2): 342-357.

20. QUAAK I. The dynamics of autism spectrum disorders: How neurotoxic compounds and neurotransmitters interact. Int. J. Environ. Res. Public Health. 2013; 10(8), 3384-3408.

21. REDERD BF, et al. Autismo diante do raciocínio lógico matemático: Fatores determinantes e métodos de intervenção. Ensaios Pedagógicos, 2018; 2(1): 113-124. 
22. SANTOS AAD, et al. Olhar da Família e da escola para criança com transtorno do espectro autista - TEA. Revista Liberum Accessum. 2020; 2(2); 43-58

23. SEMESATO MR, BOSA CA. Beliefs Indicating Parental Resilience in the Context of Autism. Psic.: Teor. e Pesq.2017; 33, e 33416.

24. SILVA CL, et al. The teaching-learning process of a student with autism: a case study in an inclusive school. Revista Diálogos e Perspectivas em Educação Especial. 2018; 5(2): 43-58.

25. SILVA JMA, ENGELBRECHT MR. Educação especial na perspectiva inclusiva: interação entre escola e família. Revista Libertas. 2019; 19(1): 213-233.

26. SILVA MM, et al. A Inclusão Educacional de Alunos com Autismo: Desafios e Possibilidades. Id online Rev. Mult. Psic. 2019; 13(43): 151-163.

27. WANG C, et al. Prenatal, perinatal, and postnatal factors associated with autism: A meta-analysis. Medicine. 2017; 96(18): e6696.

28. ZELDOVICH L. The evolution of 'autism' as a diagnosis, explained. Spectrum News. New York, NY, USA, 2018. 